\title{
Prosumer's impact on low voltage distribution networks
}

\author{
Sorin Dan Volosciuc ${ }^{1, *}$, and Monica Elena Dragosin ${ }^{2}$ \\ ${ }^{1}$ Lucian Blaga University of Sibiu, Faculty of Engineering, Computer Science and Electrical \\ Engineering Department, 550025, Emil Cioran Street, nr. 4, Sibiu, Romania \\ ${ }^{2}$ SDEE Transilvania South- Sibiu Subsidiary, 550253, Uzinei Street, nr. 1-7, Sibiu, Romania
}

\begin{abstract}
The use of renewable energy, within nowadays energy policy, has increased considerably all over the world in order to respond to the increasing energy consumption and to reduce the environmental impact of the electricity generation. At the beginning, the relatively low penetration levels of distributed generation does not produce problems, however, the nowadays massive increase of local power generation have led to new integration challenges in order to ensure the reliability and quality of the power supply. This paper also highlights some aspects regarding the use of the active distribution networks of low voltage to which electric energy producers are connected-the prosumers: advantages and disadvantages for the consumer and for the supplier, technical requirements for connection, identification of the problems of power quality.
\end{abstract}

\section{Introduction}

In recent decades, climate changes, rising prices on gas and oil and a growing demand for energy have become the most important topics for the international community. One solution to these problems represents the local generation of electrical power at the distribution networks level, using alternative energy resources.

Enforced by the current energy policies, the use of renewable energies has increased considerably in the European Union, gradually reducing the dependence on energy imports and the impact on the environment. In 2017, Sweden was the first with $54.5 \%$ of energy consumption produced using renewable energy, followed by Finland (41.0\%), Latvia (39.0\%), Denmark (35.8\%) and Austria (32.6\%) [1].

Using promotion programs and financial support, the renewable energy technologies have developed rapidly. There are several technologies based on renewable sources being able to supply electrical power at the distribution network level; these include photovoltaic (PV) systems, small wind turbines and mini hydro power plants. Availability and the cost of generated power represent the main problems with renewable resources. Wind and solar energy are not always available at the requested place and time; daily and seasonal variations, the difficulty of having an accurate forecast lead to intermittent power

\footnotetext{
* Corresponding author: sorinvolo@yahoo.com
} 
generation. Regarding the latter aspect, the price of electrical power generated using those technologies is constantly decreasing and it is expected to reach lower values for both the end consumer and at the network level.

Generating electric power at a small scale creates new patterns of the supply and demand coordination. When the final customer owns a micro power plant and produces consumes, stores or sells energy from renewable sources, it becomes a "prosumer".

There is a tendency that the photovoltaic prosumers connected to a low voltage distribution networks become an important segment in the energy sector.

\section{Impact of distributed generation (DG) on the power grids}

In the beginning, due to the low penetration levels, distributed generation (DG) did not cause problems for the distribution operators (DO); later the massive increase of local power generation became a challenge for DO having to integrate new power sources without affecting the reliability and the power quality. DG Units may affect the power quality for other users connected to the same network, due to: voltage stability (slow and / or rapid variations), voltage unbalance, frequency variations, harmonics and interharmonics, network availability and load, reactive power flow, etc.

According to this concept, power is generated in small volume units, located in most cases near the users and connected to the medium or low voltage networks. This represents the transition from passive distribution networks to active distribution networks.

We present below some aspects regarding the operation of active low voltage distribution networks [2].

a) Changing the direction of the network power flow.

In active distribution networks, a part of the energy demand is covered by classical power plants and the rest is produced near the users; if local generation exceeds consumption, the power circulates towards higher voltage levels.

b) Power Quality

DG Units may affect the power quality for other users connected to the same network.

The main problems are related to: voltage stability (slow and / or rapid variations), voltage unbalance, frequency variations, harmonics and inter-harmonics, network availability and load, reactive power flow, etc.

c) Protection Coordination

Conventional distribution networks use a relatively simple protection system based on unidirectional flow for power and fault currents. DG may change this situation because the electrical power and fault currents can be bidirectional or have at least modified amplitudes. There are four categories of protection issues:

- $\quad$ sensitivity: failure to detect defects or delayed triggering, aspects that may lead to spreading (propagation) of defects or damages, namely network instability and triggering of generating units connected to other lines of the network;

- selectivity: incorrect triggering of some DG supply lines when a fault occurs in another area of the network;

- auto- reclosing: disruptions in the auto-reclose sequences may lead to increases in the power supply interruption occurrence for some users and also to damages of the generating units;

- $\quad$ insularization any unintentional insularization must be prevented in order to ensure network security and the power quality

d) Network stability:

It implies the contribution of the DG units to the level of the network stability as well as the functioning capability within generating unit defect. 


\section{Low power photovoltaic generators}

Solar energy is inexhaustible, clean and abundant; there are several solutions for transforming it into electrical power, but the PV technology is the most common one because it converts the solar power directly and can be used for both low power applications and high power systems. Low Power photovoltaic (PV) systems can be used in two ways:

- independent systems, usually installed in rural or remote areas, but also having applications in built areas;

- $\quad$ systems connected to the public network: currently representing more than $90 \%$ of the total PV installations operating worldwide;

Currently, buildings are consuming over $40 \%$ of total energy and producing $24 \%$ of the greenhouse gases. As a result, PV panels integrated into the structure become a widespread technique of generating electrical power in built areas, transforming the building from consumers into electrical power producers [3].

Photovoltaic systems can be:

a) BAPV- Building Adapted PV systems: consisting in the architectural superposition of the photovoltaic system over the elements of the building. The photovoltaic elements are parallel to the building envelope or are using a structure that allows them to tilt at an optimal angle (Figure 1).

b) BIPV - Building Integrated PV systems consisting in replacing the construction elements of the building with photovoltaic modules, which fulfil different architectural functions. Using the current technologies, PV modules can be building elements bringing other benefits alongside energy production: weatherproofing, thermal insulation, sound or sun protection, and intelligent use of the natural light use (Figure 2).

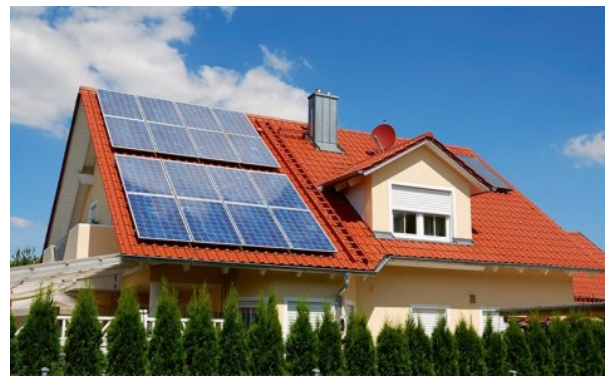

Fig. 1. System Building Adapted PV systems - BAPV

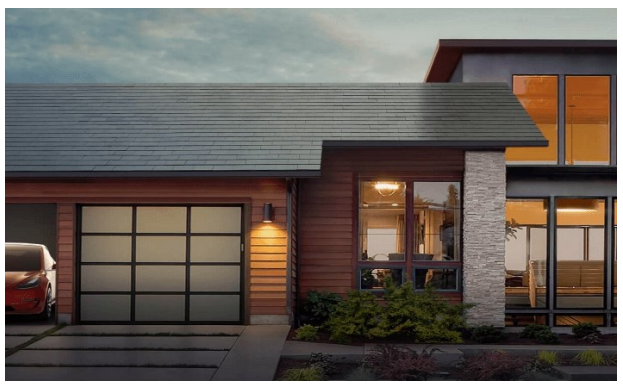

Fig. 2. System Building Integrated PV systems - BIPV

Rooftop mounted PV systems are producing clean energy for about $95 \%$ of their lifetime (30 years or more); Influenced by various factors, the investment recovery time for a PV plant decreases permanently, at a rate depending on geographic location and on the technology used. For example, the investment recovery time is 2.5 years in northern Europe and 1.5 years or less, depending on technology, in the south [4].

There are photovoltaic systems installed on individual buildings, or office buildings or buildings with other purposes. They consist of the following elements (Figure 3).

- PV panel, commonly named PV generator;

- an inverter (converts the continuous voltage generated by the panel in alternative voltage);

- metering equipment for both power delivered and power consumed from the network. 


\section{Prosumers}

\subsection{Support Policies for Prosumers}

The Regulatory package approved Romanian National Energy Regulatory Authority (ANRE) at the end of 2018 established the right of end consumers to become prosumers and to be remunerated for the power delivered to the grid $[5,6]$.

When the final customer owns a power plants and consumes, stores or sells power generated using renewable sources, it becomes "prosumer". The prosumer concept is presented in Figure 4.

The prosumers are a new category, recently defined in the national legislative framework designed to ensure the safe operation of the public power networks, monitoring the compliance with the power quality parameters.

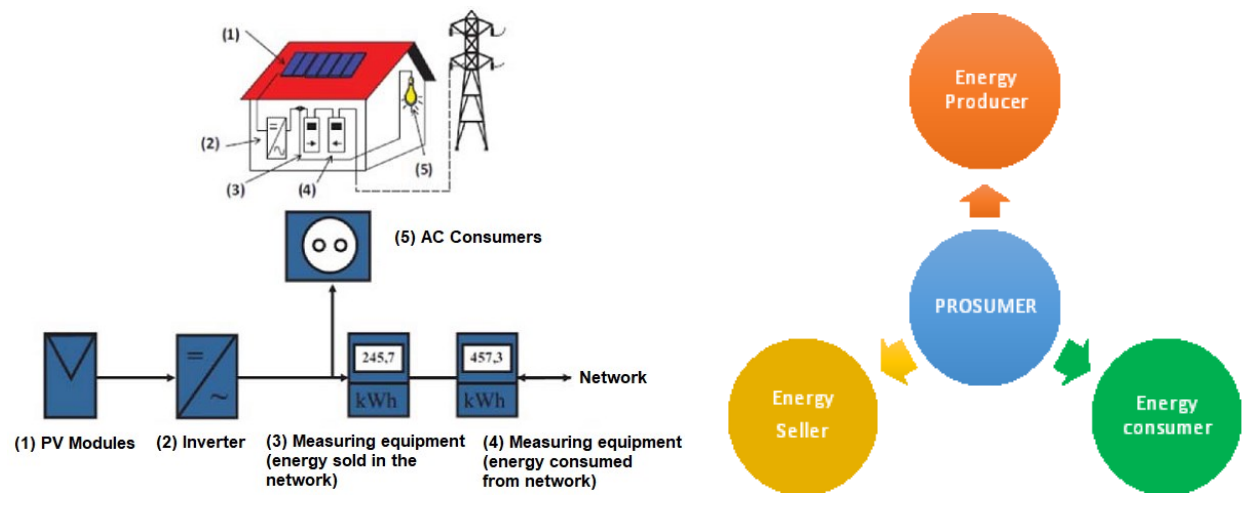

Fig. 3. Component parts of a PV system.

Fig. 4. The three roles of a prosumer.

The ANRE Orders 226, 227 and 228 issued by ANRE Regulatory Committee on 28.12.2018, contain regulations that establish the following:

- the cumulative set of demands required from an end consumer owning a power plant that generates electrical power from renewable sources for a maximum system power less than $27 \mathrm{~kW}$ per consumption site in order to be certified as a prosumer;

- the conditions for concluding the contract between the prosumer and the power supplier regarding the sale and purchase of the power produced and delivered in network;

- the calculation formula used to determine the quantity of power benefiting from the legal price if the power plant's electrical diagram contains a storage system for power generated from renewable sources that can be supplied with power from the electricity grid; - technical conditions for prosumer's connection; the prosumers have to ensure the power quality in the point of common coupling according to the provisions of the Performance Standard in effect and to avoid the use in an unbinding way;

- the possibility to market at a fair price the power produced and delivered in the network for prosumers who are not benefiting from the green certificates promotion system.

The energy produced by prosumers is purchased by the supplier at an average price equal to the weighted average price recorded in the previous year on the Day Ahead Market (DAM). On 22nd of January 2019 - OPCOM published the weighted average price recorded on DAM in 2018: 223.24 lei / MWh.

Therefore, a household consumer owning a renewable energy production facility will receive a price of 0.22232 lei for each $\mathrm{kWh}$ delivered to the grid. 


\subsection{Positive and negative aspects related to the connection of prosumers}

The integration of photovoltaic systems into low-voltage grids, correlated with the accentuated drop in photovoltaic panel prices will lead to technical challenges for the Distribution Operators in order to keep the voltage and currents within admissible limits in the context of network expansion.

Low voltage power grids have been built exclusively for supplying consumers. They are generally radial and long. The prosumers emergence leads the following aspects:

a) Positive Aspect:

A moderate number of photovoltaic panels connected on a low-voltage distribution network, provides new power injections into the grid, assures the Energo -commercial losses redistribution and helps keeping the voltage values within admissible limits.

b) Negative aspects:

A large number of prosumers delivering power will overload the low voltage network $(0,4 \mathrm{kV})$ over its capacity leading implicitly to the possibility of the occurrence of the deforming regime due to a large number of inverters mounted on photovoltaic panels.

Installing high-power photovoltaic panels without storage capacities fail to provide the injections needed in the network at peak load or during the evening when the photovoltaic panels do not produce power.

\subsection{Case Study}

Electrical power generation in different points of the low voltage network with the existence of the prosumers imposes that case studies should be carried out and solutions found in order to incorporate within the system the energy produced by the prosumers.

The study monitored the power quality parameters the prosumers are required to fulfil. Also, another important aspect monitored was the amount of power supplied by the prosumers in the distribution network. Monitoring the quality indicators at the interface between the network operators and the prosumers and supervising the framing of disturbances within the allocated limits, represent actions that have an important role to ensure the proper functioning of the power supply, the limitation of the disturbance background in the network and to ensure the level of the quality for all users of the system.

The analysed data were recorded between December 2018 and February 2019 for two prosumers, connected at the low voltage level to the distribution network belonging SDEE Transylvania South- Sibiu Subsidiary.

I. Prosumer 1 - situated in Sibiu, Calea Dumbrăvii, connected to the low voltage distribution network through a three-phase connection.

The photovoltaic system consists in a total of 40 panels, with a nominal power per panel $\mathrm{Pi}=250 \mathrm{Wp}(\mathrm{dc})$. Maximum system power is $\mathrm{P}_{\max }=10 \mathrm{~kW}(\mathrm{dc})$.

The inverter has the following characteristics: Nominal voltage Un=400V, Output Power Pi $=10 \mathrm{~kW}(\mathrm{ac})$

Maximal simultaneous power delivered in the network $9 \mathrm{~kW}$

Maximal simultaneous power received from the network $9 \mathrm{~kW}$.

II. Prosumer 2 - situated in Sibiu, street H. Heine, connected to the low voltage distribution network through a three-phase connection.

The photovoltaic system consists in a total of 20 panels, with a nominal power per panel $\mathrm{Pi}=245 \mathrm{Wp}(\mathrm{dc})$. Maximum system power is $\mathrm{P}_{\max }=4.9 \mathrm{~kW}(\mathrm{dc})$.

The inverter has the following characteristics: Nominal voltage Un $=400 \mathrm{~V}$, Output Power $\mathrm{Pi}=4.9 \mathrm{~kW}(\mathrm{ac})$

Maximal simultaneous power delivered in the network $4.9 \mathrm{~kW}$

Maximal simultaneous power received from the network $9 \mathrm{~kW}$. 


\subsubsection{Energy exchange}

There is a tendency that the photovoltaic prosumers connected to the low voltage network should become an important segment in the energy sector.

We present the load curves for the two monitored prosumers in Figure 5.

The most used methodology for the determination of the load curve profile consists in the statistical processing of the load profile, recorded in the format of 24 hourly levels.

In the chart there are presented the hourly production and hourly consumption. It may be observed that a part of the produced energy is used for internal consumption, the rest of it is delivered into the network and sold to the supplier. In both situations, the power injection in the low voltage network does not go beyond $3.5 \mathrm{~kW}$.

We draw a comparison between the daily consumption of the building and the electricity generated by the PV system, for January 2019, in Figure 6.
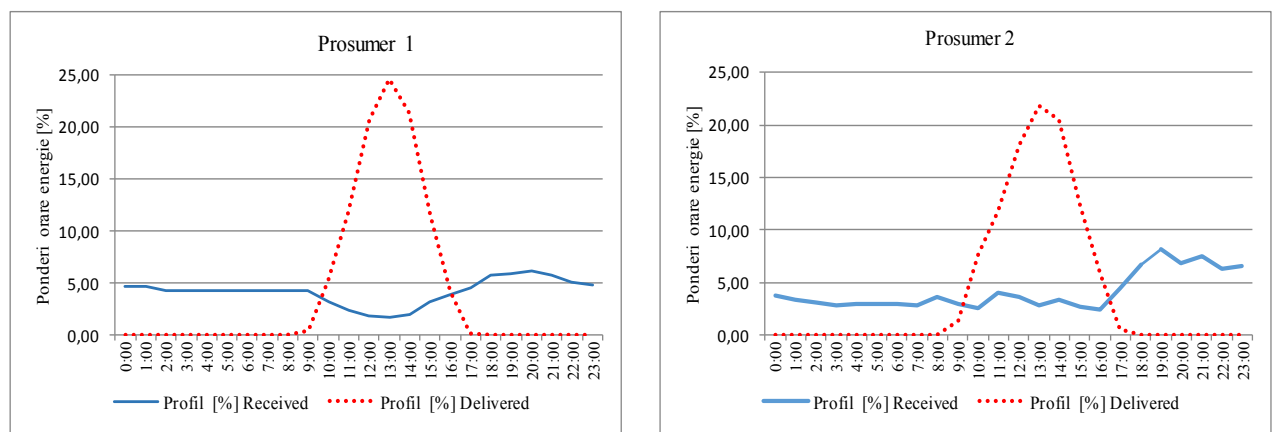

Fig. 5. Load/Generation profile of prosumers during winter
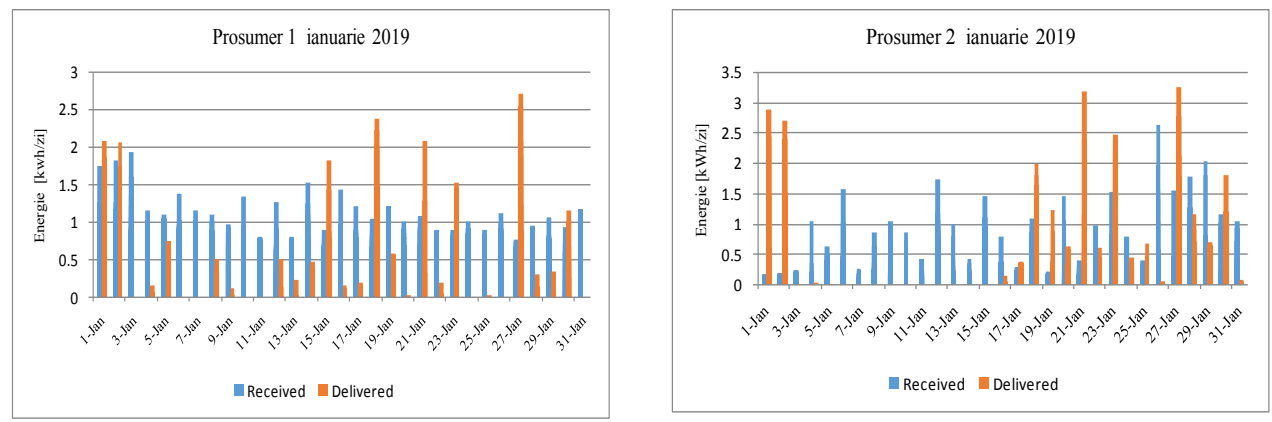

Fig. 6. Comparison between the daily consumption and the electricity generated by the PV system

The electrical power produced by low-power photovoltaic panels $(3-6 \mathrm{~kW})$ is used to cover self-consumption, with a non-significant quantity delivered to the network.

If the maximum system power increases up to $27 \mathrm{~kW}$, the production exceeds the needs of the prosumers. Higher system power causes problems in the distribution operators network: overloads, unbalanced operating regimes resulting from the large number of inverters.

Also, the energy flow on the low voltage network changes from the classic situation and the low voltage surplus power can be redistributed in reverse circulation to the medium voltage network through the transformers. 


\subsubsection{Voltage}

According to current norms during normal operating mode, the prosumer injecting active power into the network, is not allowed to generate in the point of coupling/delimitation, transient voltage variations of more than $\pm 5 \%$ of the nominal voltage of the network it is connected to.

The values obtained for voltage; for each phase voltage values stayed within admissible limits and no event occurred are presented in Figure 7.
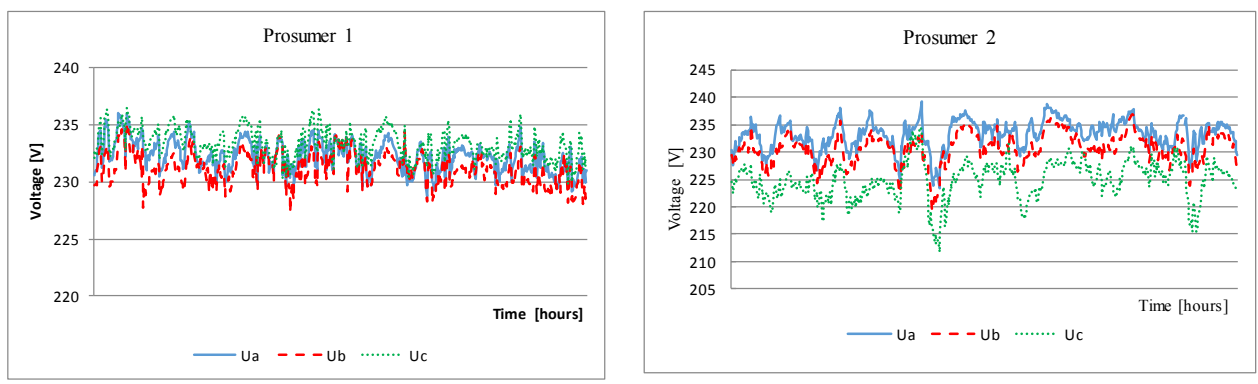

Fig. 7. Recorded Voltage Values

\section{Conclusions}

Current energy policies and technical developments have led to a significant increase in distributed generation based on renewable energy sources (RES); the integration of distributed generation (DG) systems into the public networks is important because they reduce the environmental impact and allow the introduction of RES into distribution networks.

Using promotion programs and financial support, renewable energy technologies have developed rapidly and local energy production has also increased, gradually reducing dependence on energy imports and the impact on the environment.

The use of DG units represents the transition from passive distribution networks to active distribution networks. Low penetration levels do not represent a problem for the DOs, but a massive increase in DG may affect the reliability and the power quality of the network. A few disadvantages of a higher penetration level are presented below:

- $\quad$ the power quality may be affected because most DG systems are connected to the grid through electronic converters;

- negative influence on the operation of the protection systems which exist in the electric network;

- increased power losses or even change in network power flow;

The generating electric power systems through photovoltaic installations placed on the surface of the buildings may be combined with other functions of the buildings which require usable electric power. The use of the local production of energy meets the demand of the electric power consumption of the building, thus avoiding the loss related to the distribution, reducing the investment and the maintenance costs for utilities.

Electrical power generation in different points of the low voltage network with the existence of the prosumers imposes that case studies should be carried out and solutions found in order to incorporate the energy produced by the prosumers within the system.

The tendency, for the following period of time, is to make the photovoltaic prosumers connected to the low voltage network an important part of the electric field + . The prosumers 
will contribute to the new business models, new segments and other values on the market of the traditional companies of electric energy.

\section{References}

1. https://ec.europa.eu/eurostat/documents/2995521/9571695/8-12022019-AP-EN.pdf /b7d237c1ccea-4adc-a0ba-45e13602b428

2. M. Chindris, A. Cziker, A. Miron, Small Distributed Renewable Energy Generation for Low Voltage Distribution Networks, Problemele energeticii regionale (2016)

3. F. Azadian, M.A.M.Radzi, Renew Sust Energ Rev., 22, 527-538 (2013)

4. Fraunhofer Institute for Solar Energy Systems, ISE. Photovoltaics Report, (2015)

5. ANRE, Ordin nr.226 pentru aprobarea regulilor de comercializare a energiei electrice produsă in centrale electrice din surse regenerabile cu putere electrică instalată de cel mult $27 \mathrm{~kW}$ aparţinând prosumatorilor (2018)

6. ANRE, Ordin nr.228 pentru aprobarea Normei Tehnice Condiţii tehnice de racordare la reţelele electrice de interes public pentru prosumatorii cu injecţie de putere activă în reţea (2018)

7. ANRE, Ordin nr.11 Standardul de performanţă pentru serviciul de distribuţie e energiei electrice (2016)

8. PARLAMENTUL ROMANIEI, Legea 220/2008 cu modificarile si completarile ulterioare, pentru stabilirea sistemului de promovare a producerii energiei din surse regenerabile de energie Bucuresti ( 2008)

9. European Commission, A European Strategic Energy Technology Plan (SET-Plan). Technology Map, 1510, Brussels SEC (2007)

10. European Commission, Directive of the European Parliament and of the Council on the promotion of the use of energy from renewable sources, (2008)

11. European Commission. European energy security strategy, 330 final COM (2014) 